\title{
STRATEGI PENGEMBANGAN SUMBER DAYA MANUSIA PADA CV. FAJAR CENDEKIA INTERMEDIA KOTA JAYAPURA
}

\author{
Daniel Ayub Dawan ${ }^{1}$ \\ dawandaniel31@yahoo.com
}

\begin{abstract}
Abstrak
Penelitian ini bertujuan untuk mengetahui Bagaimana Stategi pengembangan Sumber Daya Manusia pada CV. Fajar Cendekia Intermedia dan Faktor - faktor apa saja yang mempengaruhi strategi pengembangan Sumber Daya Manusia pada CV. Fajar Cendekia Intermedia. Diharapkan dengan adanya penelitian ini mampu meningkatkan pengembangan SDM sehingga berdampak pada meningkatan pendapatan perusahaan. Desain yang digunakan dalam penelitian ini adalah expost facto dengan One Shoot Case Study yang menggambarkan fenomena nyata yang terjadi di lapangan. Penelitian ini dilaksanakan di usaha fotocopy CV. Fajar Cendekia Intermedia Kota Jayapura. Subjek penelitian ini adalah pemilik perusahaan dan karyawan yang bekerja di fotocopy CV. Fajar Cendekia Intermedia Kota Jayapura. Untuk mengetahui strategi pemasaran dilakukan dengan menggunakan analisis SWOT. Hasil penelitian menunjukkan bahwa kondisi internal usaha jasa fotocopy CV. Fajar Cendekia Intermedia Kota Jayapura memiliki nilai 3,01 yang dapat diartikan kekuatan perusahaan baik dengan penilaian skala likert. Sedangkan pada kondisi eksternal usaha jasa fotocopy tersebut memiliki nilai 3,44 yang dapat diartikan nilai peluang tinggi dengan penilaian skala likert. Sistem kerja yang diterapkan usaha jasa fotocopy CV. Fajar Cendekia Intermedia Kota Jayapura efektif dengan ditunjukkan nilai bobot item 0,49 yang dapat diartikan poin tersebut memiliki tingkat ancaman paling rendah dibandingkan ancaman lainnya. Posisi usaha jasa fotocopy tersebut saat ini berada pada fase pertumbuhan usaha dan dibuktikan dengan matriks internal dan eksternal SWOT yang menunjukkan keadaan perusahaan berada pada sel 1. Strategi yang tepat diterapkan usaha jasa fotocopy CV. Fajar Cendekia Intermedia Kota Jayapura saat ini adalah dengan strategi SO (Strength Opportunities).
\end{abstract}

Kata kunci: SWOT, Strategi Pemasaran, Sumberdaya Manusia

\footnotetext{
${ }^{1}$ Fakultas Ekonomi dan Bisnis Universitas Cendrawasih
} 


\begin{abstract}
This study aims to determine how the human resource development strategy at $C V$. Fajar Cendekia Intermedia and what factors influence the strategy of developing Human Resources at CV. Fajar Scholar Intermedia. It is hoped that this research will be able to improve HR development so that it has an impact on increasing company income. The design used in this research is ex-post facto with One Shoot Case Study which describes real phenomena that occur in the field. This research was conducted in a photocopy of CV. Fajar Cendekia Intermedia Jayapura City. The subjects of this research are company owners and employees who work on photocopies of CV. Fajar Cendekia Intermedia Jayapura City. To find out the marketing strategy is done by using a SWOT analysis. The results showed that the internal conditions of the $C V$ photocopy service business. Fajar Cendekia Intermedia Jayapura City has a score of 3.01 which can be interpreted as a good company strength with a Likert scale rating. Meanwhile, the external condition of the photocopying service business has a value of 3.44 which can be interpreted as a high opportunity value with a Likert scale assessment. The work system applied by the CV photocopy service business. Fajar Cendekia Intermedia Jayapura City is effective with the indicated item weight value of 0.49 which means that this point has the lowest threat level compared to other threats. The position of the photocopying service business is currently in the business growth phase and is evidenced by the internal and external SWOT matrix which shows the company's condition is in cell 1. The right strategy is applied to the CV photocopying service business. Fajar Cendekia Intermedia in Jayapura City is currently using the SO (Strength Opportunities) strategy.
\end{abstract}

Keywords: SWOT, Marketing Strategy, Human Resources

\title{
A. Pendahuluan
}

Peranan Sumber Daya Manusia dalam Bisnis adalah sebagai alat penggerak Internal Perusahaan yang memanfaatkan seluruh fasilitas dalam perusahaan untuk mencapai tujuan. Sumber Daya Manusia yang baik akan dapat mencapai hasil yang maksimal apabila di kelola dengan cara terencana, terorganisir, terkendali, terawasi dan didukung ketepatan memotivasi. Sesuai dengan yang disampaikan Rochaeni (2008) bahwa kualitas modal manusia (human capital quality) menekankan fungsi manusia (karyawan) sebagai faktor penentu keberhasilan organisasi yang amat penting selain modal finansial, teknologi, material. Lemahnya kemampuan mutu SDM akan membawa implikasi pada kemampuan berprestasi, daya kreasi dan keberlangsungan suatu organisasi dalam menghadapi era kompetisi dan tantangan global menurut Andhika Kharismawan dan Dwi Ratna Hidayati (2016:66).

Sumber Daya Manusia (SDM) menjadi unsur utama dalam segala aktifitas yang dilakukan, meskipun menggunakan alat yang canggih dan handal namun tanpa dibarengi peran aktif SDM yang baik, peralatan tersebut tidak akan bekerja secara maksimal. Kinerja karyawan yang baik dapat di lihat dari berbagai sisi. Oleh karena itu, penilaian kinerja sangat perlu di lakukan perusahaan untuk mengetahui sejauh mana karyawan mampu berperan dalam pertumbuhan dan perkembangan karyawan.CV Fajar Cendekia Intemedia merupakan salah satu Perseroan 
Comanditer swasta yang menawarkan jasa Percetakan, pelayanan jasa transportasi, khususnya jasa Travel dan Tours, Ketatnya persaingan yang terjadi antar perseroan mempengaruhi kualitas SDM pada perusahaan.

Berkaitan dengan uraian tersebut di atas untuk dapat menangani kegiatan sumber daya manusia , tentunya pihak perusahaan harus mampu mengembangkan sumber daya manusia dalam mengikuti berbagai macam perubahan. Agar sebuah organisasi dapat bergerak dengan cepat dan fleksibel, terutama dalam memanfaatkan peluang organisasi harus berusaha agar setiap orang yang ada di dalamnya berperan serta menyumbangkan dan mengembangkan gagasan dan ide, karena hanya organisasi yang fleksibel dan adaptif yang mampu bersaing dalam era persaingan global yang sangat ketat sebagai dampak dari terbentuknya berbagai kesempatan bagi pelaku bisnis antar Kota. Fariansyah Hasan Basrie (2008:73). Kurang optimal terutama dalam pengembangan Sumber daya manusianya. Dengan mengelola sumber daya yang dimaksud, selain diperuntukkan bagi peningkatan kesejahteraan masyarakat dan yang terpenting adalah untuk meningkatkan CV Fajar Cendekia Intemedia yang nantinya dapat meningkatkan Pendapatan. Dengan permasalahan tersebut maka peneliti menarik sebuah permasalahan yaitu Bagaimana Stategi pengembangan Sumber Daya Manusia pada CV. Fajar Cendekia Intermedia dan Faktor - faktor apa saja yang mempengaruhi strategi pengembangan Sumber Daya Manusia pada CV. Fajar Cendekia Intermedia. Diharapkan dengan adanya penelitian ini mampu meningkatkan pengembangan sdm sehingga berdampak pada meningkatan pendapatan perusahaan.

\section{B. Strategi Pengembangan Sumberdaya Manusia}

Menurut Schuler dan Youngblood dalam Rivai (2008:245) menekankan bahwa mempelajari pengembangan sumber daya manusia dari organisasi, manusia sebagai bagian dari organisasi sehingga diungkapkan bahwa pengembangan sumber daya manusia pada suatu organisasi akan melibatkan berbagai variabel yaitu pendidikan dan pelatihan. Pengembangan mengarah pada kesempatankesempatan belajar yang didesain untuk mengembangkan kemampuan para karyawan. Pengembangan SDM bagi karyawan adalah suatu proses belajar dan berlatih secara sistematis untuk meningkatkan kompetensi dan kinerja mereka dalam pekerjaannya sekarang dan menyiapkan diri untuk peran dan tanggung jawab yang akan datang.

Menurut Hasibuan dalam Tilon (2013) berpendapat bahwa pengembangan adalah suatu usaha untuk meningkatkan kemampuan teknis, teoritis, konseptual, dan moral karyawan sesuai dengan kebutuhan pekerjaan/jabatan melalui pendidikan dan latihan.Menurut Effendi (2002) pengembangan dapat didefinisikan sebagai usaha yang terencana dari perusahaan untuk meningkatkan pengetahuan, keterampilan, dan kemampuan karyawan.

Robert L. Mathis dan John H. Jackson (2001:51) berpendapat bahwa perencanaan SDM adalah proses analisis dan identifikasi tersedianya dan kebutuhan akan sumber daya manusia sehingga organisasi tersebut dapat mendapat tujuan. Siagian (2002:182) selanjutnya, menjelaskan bahwa di kalangan pejabat atau petugas yang mengelola sumber daya manusia sering terdapat persepsi yang membedakan pelatihan dan pengembangan. Perbedaan tersebut intinya mengatakan 
bahwa pelatihan di maksudkan untuk membantu meningkatkan kemampuan para pegawai melaksanakan tugas sekarang, sedangkan pengembangan lebih berorientasi pada peningkatan produktifitas kerja pada pekerja di masa depan. Akan tetapi sesunggunya perbedaan tersebut tidak perlu di tonjolkan, karena manfaat pelatihan yang di tempuh sekarang akan berlanjut sepanjang karier seseorang. Berarti pengembangan bagi pegawai yang bersangkutan karena mempersiapkan memikul tanggung jawab yang lebih besar di kemudian hari.

Dari berbagai pendapat para ahli di atas dapat di simpulkan bahwa pengembangan sumber daya manusia adalah suatu langkah atau proses identifikasi atau analisis tenaga kerja untuk menduduki jabatan dan pekerjaan yang tepat dalam rangka mencapai tujuan dan sasaran yang di tetapkan organisasi.

Lingkungan internal adalah kapabilitas suatu organisasi (salusu, 1996:291) yang terdiri dari dua faktor strategi atau kekuatan dan kelemahan. Kedua faktor ini yang mempengaruhi. Jika kelemahan dalam organisasi sangat dominan maka kemungkinan kekuatan yang dimiliki organisasi akan berubah secara perlahanlahan menjadi kelemahan. Akan tetapi jika kekuatan yang dimiliki organisasi yang lebih menonjol, maka kekuatan tersebut akan di manfaatkan oleh organisasi untuk memperbaiki kelemahan. Kapasitas suatu organisasi sebagaimana di sebutkan di atas biasanya dapat di lihat dari berbagai faktor, antara lain struktur organisasi, integritas atu loyalitas dari semua karyawan kepada organisasi fasilitas yang dimiliki, disiplin, sumber daya baik dana maupun tenaga, lokasi yang strategis, integritas kepemimpinan, kesejahteraan karyawan dan lain-lain.

Pendidikan sangat penting dalam mengembangkan SDM karena pengetahuan akan diperoleh salah satunya dengan pendidikan. Orang yang tingkat pendidikannya rendah, cenderung tidak memiliki kemampuan dalam bekerja. Perusahaan pun pada dasarnya menyeleksi calon karyawan dilihat dari tingkat pendidikannya.

Strategi pengembangan SDM pada dasarnya tidak hanya melalui pendidikan dan pengembangan keterampilan, namun ada banyak cara untuk mengembangkannya. Strategi pengembangan SDM menurut Jons, 1928 dalam Sarwono, 1993, antara lain :

1. Melalui pelatihan.

Pelatihan bertujuan untuk mengembangkan individu dalam bentuk peningkatan keterampilan, pengetahuan dan sikap.

2. Pendidikan.

Pengembangan SDM melalui pendidikan bertujuan untuk meningkatkan kemampuan kerja, dalam arti pengembangan bersifat formal dan berkaitan dengan karir.

3. Pembinaan.

Pembinaan bertujuan untuk mengatur dan membina manusia sebagai sub sistem organisasi melalui program-program perencana dan penilaian, seperti man power planning, performance apparaisal, job analytic, job classification dan lain-lain.

4. Recruitment. 
Recruitment ini bertujuan untuk memperoleh SDM sesuai klasifikasi kebutuhan organisasi dan sebagai salah satu alat organisasi dalam pembaharuan dan pengembangan.

5. Melaluui Perubahan sistem.

Perubahan sistem memiliki tujuan untuk menyesuaikan sistem dan prosedur organisasi sebagai jawaban untuk mengantisipasi ancaman dan peluang faktor eksternal.

Dalam pengembangan SDM tidak boleh dilakukan secara sembarangan karena hal ini menyangkut kualitas SDM untuk sebuah organisasi atau perusahaan. SDM yang berkualitas akan membantu perusahaan untuk dapat lebih berkembang dan mencapai tujuan perusahaan.

\section{Strategi Pengembangan SDM Pada Perusahaan}

Pengembangan SDM tidak hanya dilakukan dikalangan masyarakat saja namun juga dilakukan di perusahaan dengan mengembangkan potensi karyawannya. Strategi pengembangan SDM yang dilakukan oleh perusahaan adalah :

1. Memberi kesempatan kepada karyawan untuk menyalurkan ide dan gagasan Perusahaan yang berkembang adalah perusahaan yang mau menerima ide dan gagasan dari para karyawannya. Dalam suatu perusahaan, karyawan juga berkontribusi dalam mengembangkan perusahaan atau sebagai roda penggerak suatu perusahaan. Karyawan juga butuh dihargai dengan menyediakan tempat untuk mencurahkan semua ide dan gagasan yang mereka punya. Tidak dipungkiri bahwa karyawan juga memiliki ide dan gagasan yang lebih fresh dan lebih potensial. Dengan memberikan kesempatan kepada karyawan untuk menyalurkan ide mereka, berarti membiarkan karyawan tersebut berkembang dan mengembangkan potensi yang mereka miliki. Hilangkan sikap otoriter yang tidak ingin mendengarkan ide, gagasan ataupun saran dari karyawannya karena hal tersebut hanya akan membuat karyawan menjadi tidak berkembang dan kurang produktif serta membentuk karyawan sebagai sebuah mesin untuk bekerja.

2. Memberi penghargaan.

Memberi penghargaan kepada karyawan merupakan salah satu strategi pengembangan SDM, dengan pemberian penghargaan merupakan satu bentuk apresiasi yang diberikan oleh perusahaan kepada karyawannya. Dengan adanya pemberian penghargaan kepada karyawan berprestasi, hal tersebut akan membuat karyawan lainnya termotivasi untuk dapat menjadi lebih baik. Hal tersebut akan memberi kontribusi besar terhadap perusahaan dalam mengembangkan perusahaannya.

3. Mengadakan pelatihan.

Pelatihan dilakukan bukan semata-mata untuk pribadi karyawannya saja, namun juga perusahaannya. Perusahaan tidak akan berkembang tanpa karyawan yang memiliki keterampilan dan minat kerja yang tinggi. Dengan adanya pelatihan, diharapkan mampu menggali potensi para karyawan dan mengembangkan keterampilan yang mereka miliki. 
Pengembangan SDM berarti sebuah proses yang dilakukan untuk mengembangkan potensi yang dimiliki sumber daya manusia, baik itu yang bersifat teknikal maupun non-teknikal. Dalam konteks organisasi atau perusahaan, pengembangan SDM adalah program atau kegiatan yang dilakukan HRD untuk mengembangkan kemampuan karyawan agar karyawan memberikan kinerja yang baik untuk membantu pertumbuhan perusahaan.

Prioritas strategis untuk pengembangan SDM menurut Harrison (2005) adalah untuk Meningkatkan kesadaran akan perlunya budaya belajar yang mengarah pada perbaikan berkelanjutan; Mengembangkan kompetensi manajer untuk terlibat aktif dalam pembelajaran yang mengarah pada penciptaan pengetahuan; Memanfaatkan e-learning untuk berbagi pengetahuan yang ada atau mencari pengetahuan baru.

Strategi untuk Menyukseskan Program Pengembangan SDM dalam perusahaan :

1. Melakukan kampanye kesadaran pengembangan diri;

2. Menyediakan program e-learning untuk meningkatkan employee experience dan kemampuan teknologi digital;

3. Memperkuat misi pengembangan SDM dengan mempertimbangkan core value perusahaan;

4. Memperkuat tim pelaksana program pengembangan SDM.

\section{Metode Penelitian}

Adapun lokasi penelitian yang dilakukan peneliti terdapat pada CV. Fajar Cendekia Intermedia. Dengan menggunakan Analisis kuantitatif dengan angkaangka tetapi dengan cara penggabungan berbagi informasi yang dapat dipercaya sesuai permasalahan yang ada. Data analisis kualitatif digunakan untuk menjawab masalah. Penelitian ini menggunakan Studi lapangan, Observasi, Wawancara dan Dokumentasi serta di tambah Studi kepustakaan.

Proses pengambilan keputusan strategi selalu berkaitan dengan pengembangan misi,tujuan, strategi, dan kebijakan perusahaan. dengan demikian, perencanaan strategis (strategic planner) harus menganalisis faktor-faktor strategis perusahaan (kekuatan, kelemahan, peluang, dan ancaman) dalam kondisi yang saat ini.

Berdasarkan hasil analisis SWOT, akan di rumuskan strategi pengembangan SDM pada CV. Fajar Cendekia Intermedia. Formulasi yang akan di gunakan adalah identifikasi kekuatan dan kelemahan maupun peluang dari masing-masing variabel penelitian yaitu di kombinasikan dalam matrik analisi SWOT.Analisis data bertujuan untuk menyerderhanakan seluruh data yang terkumpul, menyajikan secara sistematik, kemudian mengolah, menafsirkan, dan memaknai data tersebut.

Permasalahan dalam penelitian ini akan dianalisis secara deskriptif kualitatif, analisis IFAS (Internal Factors Analysis Summary) dan EFAS (External Factors Analysis Summary) serta analisis SWOT(Strengths Weaknesses Opportunities Threats) untuk merancang strategi pengembangannya. Dengan ketiga alat analisis tersebut diharapkan akan dapat memecahkan permasalahan yang akan diteliti.

\section{Tabel Matrik SWOT}




\begin{tabular}{|c|c|c|}
\hline EFAS & \begin{tabular}{|c|}
\multicolumn{1}{|c|}{ STRENGTH } \\
Tentukan 5-10 faktor- \\
faktor kekuatan internal
\end{tabular} & $\begin{array}{l}\quad \text { WEAKNESSES } \\
\text { Tentukan 5-10 faktor- } \\
\text { faktor kelemahan } \\
\text { internal }\end{array}$ \\
\hline $\begin{array}{l}\text { OPPORTUNITIE } \\
\text { S Tentukan 5-10 } \\
\text { faktor-faktor } \\
\text { peluang } \\
\text { Eksternal } \\
\end{array}$ & $\begin{array}{l}\text { Strategi SO } \\
\text { Ciptakan strategi } \\
\text { yang menggunakan } \\
\text { kekuatan untuk } \\
\text { memanfaatkan }\end{array}$ & \begin{tabular}{|l}
\multicolumn{1}{|c|}{ Strategi WO } \\
Ciptakan strategi yang \\
meminimalkan \\
kelemahan untuk \\
memanfaatkan peluang
\end{tabular} \\
\hline $\begin{array}{l}\text { TREATH } \\
S \text { Tentukan 5- } \\
10 \text { faktor } \\
\text { ancaman }\end{array}$ & \begin{tabular}{l}
\multicolumn{1}{c}{ Strategi ST } \\
Ciptakan strategi yang \\
menggunakan \\
kekuatan untuk
\end{tabular} & \begin{tabular}{l}
\multicolumn{1}{c}{ Strategi WT } \\
Ciptakan strategi yang \\
meminimalkan \\
kelemahan dan
\end{tabular} \\
\hline
\end{tabular}

Sumber : Data diolah, 2019

\section{E. Pembahasan}

Berdasarkan hasil penelitian langsung ke CV. Fajar Cendikia dalam hal ini karyawan sebagai pekerja dan hasil, dapat di identifikasi faktor yang mempengaruhi strategi pengembangan sumber daya manusia terdiri dari faktor internal dan faktor eksternal sebagai berikut.

\section{Pemberian rating}

Nilai rating diberikan dengan meminta bantuan pemilik " CV. FAJAR CENDIKIA " Photocopy Jayapura sebagai patokan. Pemilik perusahaan dianggap sebagai sumber yang paling mengerti kondisi perusahaan baik internal maupun eksternal. Hasil pemberian rating sebagai berikut:

Tabel Akumulasi Rating patokan dalam perhitungan.

\begin{tabular}{|l|l|l|}
\hline No & Indikator & Rating \\
\hline & Faktor kekuatan & \\
\hline 1 & Kualitas produk yang ditawarkan baik & 4 \\
\hline 2 & Harga produk yang ditetapkan terjangkau konsumen & 4 \\
\hline 3 & Pengaruh lokasi terhadap kelangsungan usaha yang baik & 4 \\
\hline 4 & Pelayanan kepada konsumen yang maksimal & 3 \\
\hline 5 & Jaminan kualitas produk yang baik pada konsumen & 3 \\
\hline 6 & Kerjasama yang baik dengan pihak asuransi & 3 \\
\hline No & Faktor kelemahan & Rating \\
\hline 7 & Tingkat harga jasa photocopy yang tinggi & 2 \\
\hline 8 & Tingkat harga sewa yang tinggi & 2 \\
\hline 9 & Resiko penurunan pendapatan yang tinggi & 4 \\
\hline 10 & Keterbatasan jumlah mesin photocopy yang tinggi & 2 \\
\hline 11 & Keterbatasan jumlah karyawan yang tinggi & 1 \\
\hline No & Faktor peluang & Rating \\
\hline 12 & Kemampuan menangkap pangsa pasar yang baik & 4 \\
\hline 13 & Jalinan kerjasama perusahaan dengan konsumen yang & 3 \\
& Baik & \\
\hline
\end{tabular}




\begin{tabular}{|l|l|l|}
\hline 14 & Dampak positif dari keragaman produk yang ditawarkan & 3 \\
\hline 15 & Citra perusahaan yang baik dimata konsumen & 2 \\
\hline 16 & Respon positif konsumen terhadap jasa perusahaan & 2 \\
\hline 17 & Respon positif terhadap jasa photocopy & 4 \\
\hline 18 & Respon positif terhadap jasa lain lainya & 4 \\
\hline 19 & Tingkat daya beli masyarakat & 4 \\
\hline 20 & Tingkat permintaan pasar & 4 \\
\hline No & Faktor ancaman & Rating \\
\hline 21 & Tingkat persaingan usaha yang tinggi & 4 \\
\hline 22 & Resiko usaha photocopy yang tinggi & 3 \\
\hline 23 & Resiko pekerja freelance yang tinggi & 4 \\
\hline 24 & $\begin{array}{l}\text { Tuntutan pasar dalam peremajaan mesin photocopy yang } \\
\text { Tinggi }\end{array}$ & 4 \\
\hline 25 & $\begin{array}{l}\text { Tingkat kriminalitas pencurian aset dan peralatan yang } \\
\text { tinggi }\end{array}$ & 4 \\
\hline 26 & Tingginya pertumbuhan photocopy disekitar & 3 \\
\hline
\end{tabular}

Sumber: Pemilik usaha jasa " CV. FAJAR CENDIKIA " photocopy Jayapura

\section{Pelaksanaan strategi pemasaran}

Identifikasi pada faktor internal dan eksternal pada usaha jasa " CV. FAJAR CENDIKIA " Photocopy Jayapura setelah dianalisis, kemudian diberikan bobot dan rating. Susunan tabel berikut merupakan hasil analisis yang telah dilakukan pada usaha jasa " CV. FAJAR CENDIKIA " Photocopy Jayapura yang dapat digunakan dalam pelaksanaan strategi pemasaran.

Tabel 18. Faktor Strategi Internal Usaha Jasa "CV. FAJAR CENDIKIA " Photocopy Jayapura .

\begin{tabular}{|l|c|c|c|}
\hline Faktor-Faktor Strategi Internal & $\begin{array}{c}\text { Bobot } \\
\text { item }\end{array}$ & Rating & $\begin{array}{c}\text { Bobot } \\
\text { item X } \\
\text { Rating }\end{array}$ \\
\hline Kekuatan & & & \\
\hline Kualitas produk yang ditawarkan baik & 0.105 & 4 & 0.421 \\
\hline Harga produk yang ditetapkan terjangkau konsumen & 0.100 & 4 & 0.403 \\
\hline $\begin{array}{l}\text { Pengaruh lokasi terhadap kelangsungan usaha yang } \\
\text { baik }\end{array}$ & 0.111 & 4 & 0.445 \\
\hline Pelayanan kepada konsumen yang maksimal & 0.103 & 3 & 0.311 \\
\hline Jaminan kualitas produk yang baik pada konsumen & 0.102 & 3 & 0.307 \\
\hline Kerjasama antara perusahaan dengan pihak asuransi & 0.103 & 3 & 0.311 \\
\hline Kelemahan & & & \\
\hline Tingkat harga jasa Photocopy yang tinggi & 0.069 & 2 & 0.139 \\
\hline Tingkat harga jasa sewa lainya yang tinggi & 0.071 & 2 & 0.142 \\
\hline Resiko penurunan pendapatan yang tinggi & 0.074 & 4 & 0.296 \\
\hline Keterbatasan jumlah mesin Photocopy yang tinggi & 0.083 & 2 & 0.166 \\
\hline Keterbatasan jumlah karyawan yang tinggi & 0.074 & 1 & 0.074 \\
\hline Total & & & 3.01 \\
\hline
\end{tabular}

Sumber: Data diolah. 
Total bobot item $\mathrm{x}$ rating pada tabel 18 yang bernilai 3.01 diperoleh dari penjumlahan bobot item $\mathrm{x}$ rating faktor kekuatan dan kelemahan, yang digunakan sebagai acuan titik kondisi internal pada Usaha Jasa " CV. FAJAR CENDIKIA" Photocopy Jayapura . Hasil ini digunakan untuk melihat posisi perusahaan saat ini.

Tabel Faktor Strategi Eksternal Usaha Jasa “CV. FAJAR CENDIKIA” Photocopy Jayapura

\begin{tabular}{|l|l|l|l|}
\hline Faktor-Faktor Strategi Eksternal & $\begin{array}{l}\text { Bobot } \\
\text { item }\end{array}$ & Rating & $\begin{array}{l}\text { Bobot } \\
\text { item X } \\
\text { Rating }\end{array}$ \\
\hline Peluang & & & \\
\hline Kemampuan menangkap pangsa pasar yang Baik & 0.079 & 4 & 0.316 \\
\hline Jalinan kerjasama dengan konsumen yang baik & 0.072 & 3 & 0.218 \\
\hline Dampak positif dari keragaman produk ditawarkan & 0.070 & 3 & 0.211 \\
\hline Citra perusahaan yang baik dimata Konsumen & 0.072 & 2 & 0.145 \\
\hline Respon positif konsumen terhadap jasa Perusahaan & 0.074 & 2 & 0.149 \\
\hline Respon positif terhadap jasa Photocopy & 0.077 & 4 & 0.308 \\
\hline Respon positif terhadap jasa lainnya & 0.075 & 4 & 0.303 \\
\hline Tingkat daya beli masyarakat & 0.079 & 4 & 0.316 \\
\hline Tingkat permintaan pasar & 0.059 & 4 & 0.238 \\
\hline Ancaman & & & \\
\hline Tingkat persaingan usaha yang tinggi & 0.054 & 4 & 0.216 \\
\hline Resiko usaha Photocopy yang Besar & 0.054 & 3 & 0.162 \\
\hline Resiko pekerja freelance yang tinggi & 0.049 & 4 & 0.199 \\
\hline Tuntutan Peremajaan Mesin Photocopy yang tinggi & 0.057 & 4 & 0.229 \\
\hline Tingkat Pencurian aset dan peralatan yang tinggi & 0.056 & 4 & 0.225 \\
\hline Tingginya pertumbuhan usaha Photocopy Disekitar & 0.066 & 3 & 0.198 \\
\hline Total & & & $\mathbf{3 . 4 4}$ \\
\hline Sumber: Data diah & & & \\
\hline
\end{tabular}

Sumber: Data diolah.

Total bobot item $\mathrm{x}$ rating pada tabel 19 yang bernilai 3.44 diperoleh dari penjumlahan bobot item $\mathrm{x}$ rating faktor peluang dan ancaman, yang digunakan sebagai acuan titik kondisi eksternal pada Usaha Jasa " CV. FAJAR CENDIKIA" Photocopy Jayapura . Hasil ini digunakan untuk melihat posisi perusahaan saat ini. Penilaian terhadap faktor eksternal dan internal yang dimiliki " CV. FAJAR CENDIKIA " Photocopy Jayapura dapat diperoleh total skor yang merupakan jumlah hasil perkalian bobot dengan rating. " CV. FAJAR CENDIKIA " Photocopy Jayapura memperoleh total skor 3,01 untuk faktor strategis internal, sedangkan pada faktor strategis eksternal menghasilkan total skor 3,44. Tahap selanjutnya berdasarkan total skor yang diperoleh perusahaan dalam tabel faktor strategis internal dan eksternal tersebut dapat dilihat posisi perusahaan untuk menerapkan strategi yang sesuai kondisi perusahaan saat ini dengan memasukkan total skor ke dalam matrik internal eksternal. Matrik internal-eksternal (IE) menunjukkan bahwa kondisi perusahaan berada pada sel 1 . Pada posisi tersebut perusahaan dapat menerapkan strategi pertumbuhan melalui integrasi vertikal. Pertumbuhan melalui 
vertikal dengan cara backward integration (mengambil alih fungsi supplier) atau dengan cara forward integration (mengambil alih fungsi distributor). Strategi pertumbuhan melalui integrasi vertikal merupakan strategi utama perusahaan dengan posisi pasar kompetitif yang kuat dalam industri yang berdaya tarik tinggi. Agar meningkatkan kekuatan bisnisnya atau posisi kompetitifnya, perusahaan harus melaksanakan upaya meminimalkan biaya operasional yang tidak efisien untuk mengontrol kualitas serta distribusi produk.

\section{F. Diskusi}

Dari hasil analisis data SWOT yang dilakukan pada " CV. FAJAR CENDIKIA " Photocopy Jayapura maka dapat dijabarkan sebagai berikut:

1. Kondisi internal "CV. FAJAR CENDIKIA " Transport Tours and Travel Jayapura dapat dilihat pada tabel 18 yang bernilai 3.01 diperoleh dari penjumlahan bobot item pada masing-masing indikator faktor kekuatan dan kelemahan penilaian responden dikalikan rating masing-masing indikator faktor kekuatan dan faktor kelemahan yang diberikan oleh pemilik. Kondisi internal CV. FAJAR CENDIKIA " Photocopy Jayapura dinyatakan baik karena nilai rata-rata faktor kekuatan perusahaan lebih tinggi dibandingkan nilai ratarata kelemahan perusahaan.

2. Kondisi eksternal " CV. FAJAR CENDIKIA " Transport Tours and Travel Jayapura dapat dilihat pada tabel 19 yang bernilai 3,44 diperoleh dari penjumlahan bobot item pada masing-masing indikator faktor peluang dan ancaman penilaian responden dikalikan rating masing-masing indikator faktor peluang dan ancaman yang diberikan oleh pemilik. Kondisi eksternal CV. FAJAR CENDIKIA " Photocopy Jayapura dinyatakain baik karena nilai ratarata faktor kekuatan perusahaan lebih tinggi dibandingkan nilai rata-rata kelemahan perusahaan.

3. Sistem kerja CV. FAJAR CENDIKIA " Photocopy Jayapura dengan menerapkan sistem kerja freelance efektif bagi bagi perusahaan karena sistem kerja freelance bukan merupakan ancaman yang berarti pada CV. FAJAR CENDIKIA " Photocopy Jayapura, selain itu dari segi financial sistem kerja freelance efektif untuk meminimalkan biaya operasional perusahaan.

4. Posisi perusahaan saat ini berada dalam posisi sel 1 yang menunjukkan pertumbuhan usaha. Pada sel.1 matrik internal-eksternal (IE) nilai internal dan eksternal CV. FAJAR CENDIKIA " Photocopy Jayapura memiliki nilai lebih dari 3, yang dapat disimpulkan perusahaan dalam posisi yang kuat dan peluang yang ditawarkan tinggi. Identifikasi pada faktor internal dan eksternal maka dapat menciptakan empat strategi utama, yaitu: strategi SO (strength dan opportunities), strategi WO (weakness dan opportunities), strategi ST (strength dan treats) dan strategi WT (weakness dan treats) yang secara rinci dapat dilihat pada tabel berikut:

Tabel Strategi SWOT.

\begin{tabular}{|c|l|l|}
\hline SES & $\begin{array}{l}\text { STRENGHT } \\
\text { Respon baik masyarakat } \\
\text { terhadap produk yang } \\
\text { ditawarkan }\end{array}$ & $\begin{array}{l}\text { Tingkat harga } \text { Photocopy yang } \\
\text { tinggi }\end{array}$ \\
\hline
\end{tabular}




\begin{tabular}{|c|c|c|}
\hline \multirow{5}{*}{ EFS } & $\begin{array}{l}\text { Harga produk yang } \\
\text { ditetapkan terjangkau } \\
\text { konsumen }\end{array}$ & $\begin{array}{l}\text { Tingkat harga sewa yang } \\
\text { tinggi }\end{array}$ \\
\hline & $\begin{array}{l}\text { Pengaruh lokasi terhadap } \\
\text { kelangsungan usaha yang } \\
\text { baik }\end{array}$ & $\begin{array}{l}\text { Resiko penurunan pendapatan } \\
\text { yang tinggi }\end{array}$ \\
\hline & $\begin{array}{l}\text { Pelayanan kepada konsumen } \\
\text { yang maksimal }\end{array}$ & $\begin{array}{l}\text { Keterbatasan jumlah mesin } \\
\text { Photocopy yang tinggi }\end{array}$ \\
\hline & $\begin{array}{l}\text { Jaminan kualitas produk } \\
\text { yang baik pada konsumen }\end{array}$ & $\begin{array}{l}\text { Keterbatasan jumlah } \\
\text { karyawan yang tinggi }\end{array}$ \\
\hline & $\begin{array}{l}\text { Kerjasama yang baik antara } \\
\text { perusahaan dengan pihak } \\
\text { asuransi. }\end{array}$ & \\
\hline OPPORTUNITIES (O) & STRATEGI (SO) & STRATEGI (WO) \\
\hline $\begin{array}{l}\text { Kemampuan menangkap } \\
\text { pangsa pasar yang baik }\end{array}$ & $\begin{array}{l}\text { Mengintensifkan promosi } \\
\text { pada pasar konsumen yang } \\
\text { akan dituju }\end{array}$ & $\begin{array}{l}\text { Menerapkan harga yang } \\
\text { bersaing pada produk yang } \\
\text { ditawarkan }\end{array}$ \\
\hline $\begin{array}{l}\text { Jalinan kerjasama } \\
\text { perusahaan dengan } \\
\text { konsumen yang baik }\end{array}$ & $\begin{array}{l}\text { Selalu berinovasi pada } \\
\text { produk yang ditawarkan }\end{array}$ & $\begin{array}{l}\text { Memberikan pilihan Jasa } \\
\text { pelayanan dengan harga } \\
\text { terjangkau }\end{array}$ \\
\hline $\begin{array}{l}\text { Dampak positif dari } \\
\text { keragaman produk yang } \\
\text { ditawarkan }\end{array}$ & $\begin{array}{l}\text { Memberikan jaminan } \\
\text { kualitas terhadap produk } \\
\text { yang ditawarkan }\end{array}$ & $\begin{array}{l}\text { Menggunakan media promosi } \\
\text { yang tepat untuk menarik } \\
\text { minat pasar }\end{array}$ \\
\hline $\begin{array}{l}\text { Citra perusahaan yang baik } \\
\text { dimata konsumen }\end{array}$ & $\begin{array}{l}\text { Memberikan pelayanan yang } \\
\text { maksimal kepada konsumen }\end{array}$ & $\begin{array}{l}\text { Menambah jumlah Mesin baik } \\
\text { dari Sewa maupun pembelian } \\
\text { baru }\end{array}$ \\
\hline $\begin{array}{l}\text { Respon positif } \\
\text { konsumen terhadap } \\
\text { jasa perusahaan }\end{array}$ & $\begin{array}{l}\text { Menambah fasilitas lagi } \\
\text { yang menjadi daya tarik } \\
\text { Konsumen }\end{array}$ & $\begin{array}{l}\text { Menambah jumlah } \\
\text { karyawan pada sektor yang } \\
\text { mengalami kekurangan }\end{array}$ \\
\hline $\begin{array}{l}\text { Respon positif terhadap jasa } \\
\text { Photocopy }\end{array}$ & & \\
\hline $\begin{array}{l}\text { Respon positif terhadap jasa } \\
\text { lainya }\end{array}$ & & \\
\hline $\begin{array}{l}\text { Tingkat daya beli } \\
\text { Masyarakat }\end{array}$ & & \\
\hline \multicolumn{3}{|l|}{ Tingkat permintaan Pasar } \\
\hline THREATS (T) & STRATEGI (ST) & STRATEGI (WT) \\
\hline $\begin{array}{l}\text { Tingkat persaingan } \\
\text { usaha yang tinggi }\end{array}$ & $\begin{array}{l}\text { Menerapkan harga yang } \\
\text { bersaing pada produk yang } \\
\text { ditawarkan }\end{array}$ & $\begin{array}{l}\text { Menetapkan harga yang } \\
\text { kompetitif namun tidak } \\
\text { merugikan bagi perusahaan }\end{array}$ \\
\hline $\begin{array}{l}\text { Resiko usaha Photocopy } \\
\text { yang tinggi }\end{array}$ & $\begin{array}{l}\text { Memberikan } \\
\text { pengamanan pada } \\
\text { unit usaha }\end{array}$ & $\begin{array}{l}\text { Pemilihan karyawan yang } \\
\text { kompeten dan dapat dipercaya }\end{array}$ \\
\hline $\begin{array}{l}\text { Resiko pekerja } \\
\text { freelance yang tinggi }\end{array}$ & $\begin{array}{l}\text { Menarik karyawan } \\
\text { dengan pertimbangan } \\
\text { yang matang }\end{array}$ & $\begin{array}{l}\text { Menarik pangsa pasar yang } \\
\text { sesuai dengan tujuan } \\
\text { perusahaan }\end{array}$ \\
\hline
\end{tabular}




\begin{tabular}{|l|l|l|}
\hline $\begin{array}{l}\text { Tuntutan pasar dalam } \\
\text { peremajaan } \\
\text { Mesin yang tinggi }\end{array}$ & $\begin{array}{l}\text { Menggunakan } \\
\text { Mesin dengan tahun } \\
\text { pembuatan dibawah 5 } \\
\text { tahun. }\end{array}$ & $\begin{array}{l}\text { Meningkatkan keamanan pada } \\
\text { Mesin yang Dioperionalkan }\end{array}$ \\
\hline $\begin{array}{l}\text { Tingkat kriminalitas } \\
\text { pencurian Aset dan } \\
\text { peralatan yang tinggi }\end{array}$ & $\begin{array}{l}\text { Mempunyai inovasi } \\
\text { sehingga memiliki } \\
\text { karakter dibanding } \\
\text { usaha lain }\end{array}$ & $\begin{array}{l}\text { perawatan Mesin } \\
\text { rutin sehingga } \\
\text { meminimalkan resiko } \\
\text { bagi perusahaan }\end{array}$ \\
\hline $\begin{array}{l}\text { Tingginya pertumbuhan } \\
\text { usaha serupa disekitar }\end{array}$ & & \\
\hline
\end{tabular}

Sumber: Data diolah.

Berdasarkan keterangan pada tabel internal faktor strategi/tabel eksternal faktor strategi (IFS/EFS) tersebut maka dapat dijabarkan sebagai berikut:

- Strategi SO (strength dan opportunities) Strategi ini dilakukan untuk memanfaatkan kekuatan perusahaan guna menangkap peluang yang dimiliki perusahaan. Menggunakan media promosi yang tepat sasaran sesuai pasar yang akan dituju oleh perusahaan sehingga tepat sasaran. Melakukan inovasi terhadap jenis produk yang ditawarkan dan menjamin kualitas produk yang ditawarkan serta memberikan pelayanan yang maksimal kepada konsumen untuk mendapatkan citra baik perusahaan dimata konsumen.

- Strategi ST (strength dan treats) Strategi ini diterapkan dimana kekuatan yang dimiliki perusahaan digunakan untuk mengatasi ancaman yang mungkin dapat dihadapi " CV. FAJAR CENDIKIA" Transport Tours and Travel Jayapura . Perusahaan dapat menetapkan harga yang bersaing untuk menghindari ancaman dari tumbuhnya usaha dibidang yang sama serta perushaan akan unggul apabila kendaraan yang ditawarkan adalah mesin dengan tahun pembuatan baru. Untuk mengatasi ancaman “CV. FAJAR CENDIKIA " Photocopy Jayapura juga dapat menggunakan tekhnologi GPS sebagai alat pengaman kendaraan agar terhindar dari tindakan kriminalitas. Perusahaan juga harus menguatkan citra baik dimata konsumen agar usaha yang dijalankan " CV. FAJAR CENDIKIA "Photocopy Jayapura tetap konsisten.

- Strategi WO (weakness dan opportunities) Strategi ini diterapkan pada saat adanya peluang yang dimiliki perusahaan guna mengatasi ancaman usaha. Perusahaan harus melakukan inovasi untuk menangkap peluang yang ada agar mempunyai karakter dimata konsumen, serta menetapkan harga produk yang kompetitif agar tidak kalah dengan perusahaan lain. Perusahaan juga perlu melakukan peremajaan pada mesin sesuai dengan kebutuhan pasar saat ini dan perlu adanya pengamanan pada kendaraan agar meminimalkan resiko tindak kejahatan pada pencurian aset dan peralatan perusahaan.

- Strategi WT (weakness dan treats) Strategi ini diterapkan saat perusahaan harus mampu mengatasi kelemahan yang dimiliki perusahaan agar terhindar dari ancaman usaha yang akan dihadapi. Perusahaan harus mampu mencukupi kekurangan mesin dan karyawan yang menjadi kekurangan dari perusahaan. Fokus dalam membidik pangsa pasar agar tujuan dari perusahaan dapat terpenuhi terlebih dahulu. Pemilihan karyawan tidak tetap sesuai dengan keahlian namun dapat dipercaya kinerjanya misalkan dengan rekomendasi 
Strategi pemasaran yang tepat diterapkan pada " CV. FAJAR CENDIKIA " Photocopy Jayapura untuk saat ini adalah menerapkan strategi SO (strength Opportunities). Strategi SO (strength dan opportunities) ini dilakukan untuk memanfaatkan kekuatan perusahaan guna menangkap peluang yang dimiliki perusahaan. Menggunakan media promosi yang tepat sasaran yaitu media promosi dengan jaringan internet karena media promosi dengan jaringan internet sangat tepat digunakan pada era modern, konsumen dapat mengakses permintaannya dengan mudah dan fleksibel karena dapat dilakukan dimana saja dan kapan saja. " CV. FAJAR CENDIKIA " Photocopy Jayapura melakukan pemasaran dengan media whatsapp masanger dengan dan website. Selain itu, " CV. FAJAR CENDIKIA " Photocopy Jayapura juga bekerjasama dengan beberapa hotel di Kota jayapura sebagai mitra kerja untuk memenuhi kebutuhan jasa ATK ketika sedang ada kegiatan di wilayah Jayapura. Media promosi dengan jaringan internet dapat meminimalkan biaya operasional perusahaan. Melakukan inovasi terhadap jenis produk yang ditawarkan dan menjamin kualitas produk yang ditawarkan serta memberikan pelayanan yang maksimal kepada konsumen untuk mendapatkan citra baik perusahaan dimata konsumen.

\section{G. Kesimpulan}

Berdasarkan hasil penelitian dan pembahasan, maka dapat ditarik beberapa kesimpulan sebagai berikut:

1. Hasil analisis data nilai faktor internal yaitu 3,01 didapat dari total penjumlahan rating faktor kekuatan dan kelemahan perusahaan. Nilai 3,01 memiliki arti nilai tersebut tinggi dengan penilaian skala likert. Nilai kekuatan paling tinggi terdapat pada poin lokasi usaha terhadap kelangsungan usaha dengan bobot 3,75 atau bobot item 0,110 ini menunjukkan bahwa lokasi “ CV. FAJAR CENDIKIA "Photocopy Jayapura sangat potensial. Nilai kelemahan paling tinggi terdapat pada poin kekurangan mesin photocopy pada " CV. FAJAR CENDIKIA" Photocopy Jayapura dengan bobot 2,8 atau bobot item 0,082 ini menunjukkan bahwa " CV. FAJAR CENDIKIA " Photocopy Jayapura belum siap secara maksimal dalam mencukupi permintaan konsumen.

2. Hasil analisis data nilai faktor eksternal yaitu 3,44 didapat dari total penjumlahan rating faktor peluang dan ancaman perusahaan. Nilai 3,44 memiliki arti nilai tersebut tinggi dengan penilaian skala likert. Nilai peluang paling tinggi terdapat pada poin kemampuan " CV. FAJAR CENDIKIA" Photocopy Jayapura dalam menangkap pangsa pasar dan daya beli masyarakat yang tinggi dengan bobot 3,65 atau bobot item 0,079 ini menunjukkan bahwa perusahaan mampu secara maksimal menangkap pangsa pasar dan didukung dengan daya beli yang tinggi. Nilai ancaman paling tinggi terdapat pada poin tingginya pertumbuhan usaha serupa di wilayah yang sama dengan " $\mathrm{CV}$. FAJAR CENDIKIA " Photocopy Jayapura dengan bobot 3,05 atau bobot item 0,066 ini menunjukkan bahwa perusahaan harus siap dengan ancaman eksternal.

3. Poin lain yang dapat disoroti untuk menjawab sistem kerja“CVV. FAJAR CENDIKIA " Photocopy Jayapura adalah nilai ancaman terendah terdapat pada poin pekerja freelance dengan bobot 2,3 atau bobot item 0,049 ini menunjukkan 
bahwa pekerja dengan sistem freelance tidak memiliki tingkat ancaman tinggi bagi " CV. FAJAR CENDIKIA " Photocopy Jayapura . Hasil analisis data mengenai posisi perusahaan dengan menggunakan analisis SWOT menunjukkan bahwa usaha jasa "CV. FAJAR CENDIKIA " Photocopy Jayapura berada dalam fase pertumbuhan usaha. Dengan nilai faktor internal 3,01 dan nilai faktor eksternal 3,44. Strategi pemasaran yang cocok diterapkan pada "CV. FAJAR CENDIKIA " Photocopy Jayapura adalah dengan menggunakan strategi SO (Strength Opportunities). Strategi SO dilakukan dengan memanfaatkan kekuatan perusahaan guna menangkap peluang pasar yang tinggi.

\section{H. Daftar pustaka}

Alma, Buchari. 2008. Manajemen Pemasaran dan Pemasaran Jasa. Bandung: CV. Alfabeta

Bastian, Indra. 2006. Akuntansi Sektor Publik. Jakarta: Erlangga Converse. 1992. Introduction to Marketing. Bandung: Alumni Fandy,Tjiptono. 2007. Strategi Pemasaran. Yogyakarta: Andi Offset

Fauziah, Rehan. 2011. "Strategi Pemasaran Café Kebun Kita Bogor”. Skripsi.

Bogor: Institut Pertanian Bogor

Firma, Agung. 2011. "Pengaruh Tindak Lanjut Rekomendasi Audit Manajemen terhadap Kualitas Pelayanan Jasa". Skripsi. Diambil dari http://www.digilib.unpas.ac.id/files/disk1/48/jbptunpaspp-gdl-agungfirma2395- babIII pada 11 Mei 2014 17:18

Freddy,Rangkuti. 2009. Analisis Swot Teknik Membedah Kasus Bisnis. Jakarta: PT. Gramedia

Grewal \& Levy. 2008. Marketing. New York: Mc.Graw Hill

Iriawan, Nova. 2009. "Strategi Pemasaran Dengan Analisis SWOT studi kasus pada CV. Langit Aksara Kabupaten Sleman”. Skripsi. Yogyakarta: UNY Kotler, Philip. 2002. Prinsip-Prinsip Pemasaran terjemahan, Edisi 9. Jakarta: Erlangga 2007. Marketing Management terjemahan. Jakarta: Erlangga

2008. Manajemen Pemasaran terjemahan, Edisi 12. Jakarta: Erlangga

Nasution, M. Nur. 2003. Manajemen Transportasi. Jakarta: Ghalia Indonesia

P. Guiltinan, J.P \& Gordon, W.P. 1987. Strategi dan Program Manajemen Pemasaran terjemahan Edisi Kedua. Jakarta: Erlangga

Payne, Adrian. 2001. The Essence of Service Marketing. Jakarta: Sembilan Empat Griffin, R.W \& Ebert, R.J. 1996. Memahami Sistem Bisnis, Edisi 8. Jakarta : Prenhallindo

Rismawan, Andri. 2014. “Analisis Perbedaan Hasil Belajar Dan Motivasi Belajar Mahasiswa Pekerja Paruh Waktu Dengan Yang Tidak Bekerja Pada Mahasiswa FE UNY”. Skripsi. Yogyakarta: UNY

Sarwono \& Martadireja. 2008. Bisnis Untuk Pengambilan Keputusan. Yogyakarta: Andi Offset 
Steinhoff. 1979. Small Business Management Fundamentals. Jakarta: Balai Buku Sugiyono. 2008. Metodologi Penelitian Bisnis. Bandung: Alphabeta 2011. Metode Penelitian Kualitatif dan RnD. Bandung: Alphabeta

Suharsimi, Arikunto. 2007. Prosedur Penelitian. Jakarta: PT. Rineka Cipta

Susiani. 2005. "Strategi Pemasaran Dengan Analisis SWOT Studi kasus pada PT.

Pramita Tours dan Travels. Skripsi. Yogyakarta: UNY

Swastha, Basu. 2002. Intisari Pemasaran dan Unsur-Unsur Pemasaran. Jakarta: Salemba Empat

Yuliono, Dwi. 2012. “Analisis SWOT Sebagai Landasan Merumuskan Strategi

Pemasaran Pada PT. Asli Motor Klaten. Skripsi. Yogyakarta: UNY 